\title{
Liddle syndrome misdiagnosed as primary aldosteronism resulting from a novel frameshift mutation of SCNN1B
}

\author{
Peng Fan ${ }^{1, *}$, Chao-Xia Lu', *, Di Zhang ${ }^{1}$, Kun-Qi Yang ${ }^{1}$, Pei-Pei Lu', Ying Zhang1, Xu Meng ${ }^{1}$, Su-Fang Hao', \\ Fang Luo', Ya-Xin Liu', Hui-Min Zhang ${ }^{1}$, Lei Song ${ }^{1}$, Jun Cai', Xue Zhang ${ }^{2}$ and Xian-Liang Zhou' \\ ${ }^{1}$ Department of Cardiology, Fuwai Hospital, National Center for Cardiovascular Diseases, Chinese Academy of Medical Sciences and Peking Union \\ Medical College, Beijing, China \\ ${ }^{2}$ McKusick-Zhang Center for Genetic Medicine, State Key Laboratory of Medical Molecular Biology, Institute of Basic Medical Sciences, Chinese Academy \\ of Medical Sciences and Peking Union Medical College, Beijing, China
}

Correspondence should be addressed to X Zhang or X-L Zhou: xuezhang@pumc.edu.cn or zhouxianliang0326@hotmail.com

*(P Fan and C-X Lu contributed equally to this work)

\begin{abstract}
Liddle syndrome (LS), a monogenetic autosomal dominant disorder, is mainly characterized by early-onset hypertension and hypokalemia. Clinically, misdiagnosis or missing diagnosis is common, since clinical phenotypes of LS are variable and nonspecific. We report a family with misdiagnosis of primary aldosteronism (PA), but identify as LS with a pathogenic frameshift mutation of the epithelial sodium channel $(\mathrm{ENaC}) \beta$ subunit. DNA samples were collected from a 32-year-old proband and 31 other relatives in the same family. A designed panel including 41 genes associated with monogenic hypertension was screened using next-generation sequencing. The best candidate disease-causing variants were verified by Sanger sequencing. Genetic analysis of the proband revealed a novel frameshift mutation c.1838delC (p.Pro613GInfs*675) in exon 13 of SCNN1B. This heterozygous mutation involved the deletion of a cytosine from a string of three consecutive cytosines located at codons 612 to 613 and resulted in deletion of the crucial PY motif and elongation of the $\beta$-ENaC protein. The identical mutation was also found in 12 affected family members. Amiloride was effective in alleviating LS for patients. There were no SCNN1A or SCNN1G mutations in this family. Our study emphasizes the importance of considering LS in the differential diagnosis of early-onset hypertension. The identification of a novel frameshift mutation of SCNN1B enriches the genetic spectrum of LS and has allowed treatment of this affected family to prevent severe complications.
\end{abstract}

\author{
Key Words \\ - Liddle syndrome \\ - hypertension \\ - hypokalemia \\ - frameshift mutation \\ - genetic screening
}

\section{Introduction}

Over the past two decades, with advances in the understanding of genetic diseases of renal tubular transport defects, there has been greater interest in the importance of potassium in hypertension (1). Monogenic hypertension combined with hypokalemia is seen in several disorders, such as Liddle syndrome (LS), familial primary aldosteronism (PA), apparent mineralocorticoid excess, $11 \beta$-hydroxylase deficiency and $17 \alpha$-hydroxylase deficiency (2). The phenotypic similarity increases the difficulty of diagnosis for physicians. Genetic testing is an effective strategy for diagnosis of these monogenic hypertension (3).

$$
\begin{array}{lr}
\text { https://ec.bioscientifica.com } & \text { () } 2018 \text { The authors } \\
\text { https://doi.org/10.1530/EC-18-0484 } & \text { Published by Bioscientifica Ltd }
\end{array}
$$

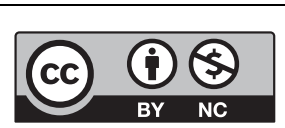


Liddle syndrome (LS, OMIM \#177200), an autosomal dominant form of monogenic hypertension, typically presents as severe hypertension with early penetrance, hypokalemia, decreased plasma concentration of renin and aldosterone and metabolic alkalosis. Mutations of the epithelial sodium channel $(\mathrm{ENaC})$ genes are capable of increasing $\mathrm{Na}^{+}$reabsorption in the distal nephron of the kidney, resulting in water and sodium retention and potassium loss (4). ENaC consists of three homologous subunits, $\alpha$-ENaC, $\beta$-ENaC, and $\gamma$-ENaC, which are encoded by SCNN1A, SCNN1B and SCNN1G, respectively (5). Most of pathogenic mutations are in the 13th exons of SCNN1B and SCNN1G and disrupt the PY motif, an essential proline-rich structure in the ENaC subunit (6). Many physicians are unfamiliar with LS, which is a rare disease clinically. Additionally, the phenotypic variability decreases the diagnostic accuracy of LS. Therefore, many LS patients are misdiagnosed and mistreated, so that severe complications develop at a young age.

In this study, we report a hypokalemic hypertensive in whom a misdiagnosis of PA was corrected by genetic analysis. A novel $S C N N 1 B$ frameshift mutation was identified, confirming the diagnosis of LS. Screening of four generations of the family members and the use of tailored medicine for LS patients provide better management of LS for the affected family members.

\section{Materials and methods}

\section{Subjects}

The proband was a 32-year-old male referred to the hypertension center of Fuwai Hospital for arterial hypertension diagnosed 13 years previously. He was investigated to exclude secondary forms of hypertension for several times and misdiagnosed as PA. This time, his clinical features including early-onset and treatmentresistant hypertension (including spironolactone) and spontaneous hypokalemia, as well as low plasma aldosterone concentration (PAC) and evident family history of early-onset hypertension, led us to suspect other forms of secondary hypertension. Therefore, 31 at-risk family members were also enrolled in this study (Fig. 1). All the participants agreed to clinical evaluation, biochemical examination and genetic testing.

\section{Compliance with ethical standards}

This study was approved by the Ethics Committee of Fuwai Hospital and has been performed in accordance with the Declaration of Helsinki. Informed consent was obtained from all individual participants included in the study.

\section{Clinical examinations}

Imaging examinations were performed during the proband's hospitalization, including echocardiography, abdomen ultrasound and CT of the kidneys, adrenal glands and renal arteries. Biochemical evaluations performed included urine protein, microalbuminuria, adrenocorticotropin and serum cortisol on different occasions. Plasma renin concentration (PRC) and PAC were measured for all the participants at Fuwai Hospital by a chemiluminescence immunoassay using the LIAISON Direct Renin kit (DiaSorin S.p.A, Vercelli, Italy) and the LIAISON Aldosterone kit (DiaSorin Inc., Stillwater, USA). The other biochemical examinations were measured using standard methods.

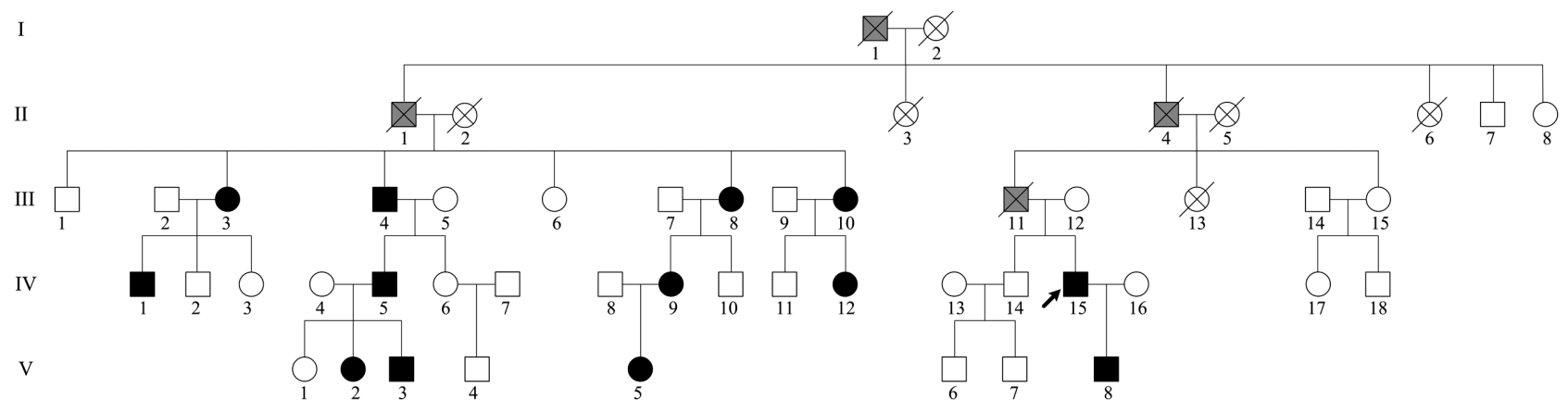

Figure 1

Family pedigree: black filled symbols - affected subjects carrying the SCNN1B c.1838delC frameshift mutation; empty symbols - not tested for epithelial sodium channel genes; grey filled symbols - probably affected subjects without genetic screening; black arrow indicates the proband.

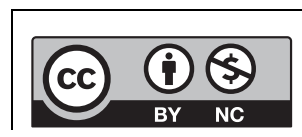

This work is licensed under a Creative Commons Attribution-NonCommercial 4.0 International License. 


\section{Sample sequencing}

We collected venous blood samples from all participants with informed consent for genetic testing. Genomic DNA was isolated from peripheral blood leucocytes using the QIA amp DNA Blood Mini kit (QIAGEN) by standard protocols. The DNA sequence of the proband was screened by a designed panel including 41 genes (Supplementary Table 1, see section on supplementary data given at the end of this article). All coding exons were enriched using custom-made SureSelect Target Enrichment System (Agilent Technologies, Inc.). Captured DNA library was sequenced on Illumina Hiseq $X$ Ten according to manufacturer's instructions for paired-end $150 \mathrm{bp}$ reads. Apart from this designed panel, we also solely detected SCNN1A for the proband. Sanger sequencing was used as a verification approach to eliminate nextgeneration sequencing-based false-positive calls and to identify whether other participants carried the candidate pathogenic mutations. PCR was performed to amplify the exon 13 of $\beta$-ENaC by the gene-specific primer pairs (7): SCNN1B: (GenBank accession number NM_000336): forward primer: 5'-CAAGAATCACCTCCCAGGAAGC-3', reverse primer: 5'-GTGATTCTACAGAGCCCTTGGC-3'. The PCR products were sequenced bidirectionally with an ABI Prism 377 DNA sequencer (Applied Biosystems).

\section{Genetic analysis}

Paired-end reads were aligned to NCBI build37 (hg19) using BWA and duplicated reads were marked by Picard (8). SNV and indel mutations were detected by SAMtools and in-house filter pipeline, and Annovar (9) was used for annotation. Common polymorphisms were excluded based on their allele frequency in the 1000 genome databases (ftp://ftp-trace.ncbi.nih.gov/1000genomes/ $\mathrm{ftp} /$ ), the ExAC database of Exome Aggregation Consortium (http://exac.broadinstitute.org/) and the esp6500si database of National Heart, Lung, and Blood Institute (NHLBI, http://evs.gs.washington.edu/EVS/).

\section{Results}

\section{Clinical and biochemical features}

The proband was first diagnosed with hypertension $(150 / 90 \mathrm{mmHg})$ without any symptoms at the age of 19 years after a physical examination, and he refused medication. At age 28 years, his blood pressure (BP) rose to 220/140 $\mathrm{mmHg}$ followed by urine occult blood and proteinuria. Oral administration of fosinopril, nifedipine and hydrochlorothiazide failed to control his BP, which ranged from 150 to $180 \mathrm{mmHg}$ for systolic pressure and from 90 to $120 \mathrm{mmHg}$ for diastolic pressure. He was found to have hypokalemia with serum potassium levels fluctuating between 2.56 and $3.25 \mathrm{mmol} / \mathrm{L}$. ARR (PAC 12ng/dL, Plasma Renin Activity, PRA, $0.8 \mathrm{ng} / \mathrm{mL} / \mathrm{h}$, ARR 15) did not match with diagnostic criteria of PA. And captopril challenge (PAC $16 \mathrm{ng} / \mathrm{dL}$, PRA $13.24 \mathrm{ng} / \mathrm{mL} / \mathrm{h}$ ) and saline infusion (PAC $16 \mathrm{ng} / \mathrm{dL}$, PRA $0.49 \mathrm{ng} / \mathrm{mL} / \mathrm{h}$ ) tests were both false positive. A CT scan found adrenocortical nodular hyperplasia and excluded renal abnormalities. Unfortunately, he was misdiagnosed as PA based on above clinical characteristics. And then he was given spironolactone (20 mg twice a day) and undoubtedly showed no significant improvement in BP $(164 / 100 \mathrm{mmHg})$.

In March 2018, the proband was admitted to our hypertension center for evaluation of the uncontrolled high BP and hypokalemia. Biochemical measurements showed a low serum potassium $(2.86 \mathrm{mmol} / \mathrm{L})$ and urine sodium (121.13 mmol/24h), suppression of PAC (2.2 ng/dL), urine occult blood, proteinuria and microalbuminuria (Table 1). ARR (ARR 0.195, PAC 3.1 ng/dL, PRC $15.9 \mu \mathrm{IU} / \mathrm{mL}$ ) and captopril challenge test (PAC 2.6ng/dL, PRC 33.3 $\mu \mathrm{IU} / \mathrm{mL}$ ) were both negative. Echocardiography showed enlargement of the aortic sinus $(42 \mathrm{~mm})$. Hypertensive retinopathy was shown by fundus examination.

Apart from the proband, another 12 SCNN1B mutation carriers across four generations were identified with LS in this family (Fig. 1). All LS patients suffered from different levels of hypertension, and most of them had a high BP detected before the age of 30 years. Six of them showed low serum potassium or PRC, and seven of them had low PAC. IV-5 had hypertension and hypokalemia for 15 years, with headache, dizziness, malaise and epistaxis. Uncontrolled high $\mathrm{BP}$ resulted in a stroke at the age of 33 years. Two of his three children were also diagnosed with LS by genetic testing and showed typical symptoms and signs of LS. The proband's mother (III-12) was not found to have the identified mutation, while his father (III-11) died of a sudden stroke at the age of 30 years. Therefore, we speculated that III-11 also carried the pathogenic mutation, based on the autosomal dominant genetic pattern of LS and the co-separation analysis of this family.

\section{Genetic findings}

As shown in Fig. 2, a heterozygous frameshift mutation c.1838delC in exon 13 in SCNN1B was identified in the

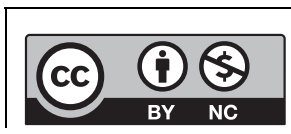

This work is licensed under a Creative Commons Attribution-NonCommercial 4.0 International License. 
Table 1 Laboratory data of the proband on admission.

Renal function
Blood urea nitrogen
Creatinine
Uric acid
Serum electrolytes
Sodium
Potassium
Chloride
Calcium
Phosphorus
Urine electrolytes
Sodium
Potassium
Urinalysis
Urine occult blood
Red blood counts
Proteinuria
Microalbuminuria
Hormone levels in serum
Renin, supine
Renin, upright
Aldosterone, supine
Aldosterone, upright
Adrenaline
Noradrenaline
Dopamine
Hormone levels in urine
Aldosterone
Big endothelin

$4.99 \mathrm{mmol} / \mathrm{L}(2.86-7.90)$

$105 \mu \mathrm{mol} / \mathrm{L}(44-133)$

$380 \mu \mathrm{mol} / \mathrm{L}(148.8-416.5)$

$142 \mathrm{mmol} / \mathrm{L}(137-147)$

$2.86 \mathrm{mmol} / \mathrm{L}(3.5-5.3)$

$105 \mathrm{mmol} / \mathrm{L}(99-110)$

$2.15 \mathrm{mmol} / \mathrm{L}(2.2-2.75)$

$1.03 \mathrm{mmol} / \mathrm{L}(0.97-1.60)$

$121.13 \mathrm{mmol} / 24 \mathrm{~h}(130-260)$ $35.47 \mathrm{mmol} / 24 \mathrm{~h}(25-125)$

$++$

$299.7 / \mu \mathrm{L}(0-25)$

$0.54 \mathrm{~g} / 24 \mathrm{~h}(0.03-0.14)$

$561.1 \mathrm{mg} / \mathrm{L}(<30)$

$4.7 \mu \mathrm{lU} / \mathrm{mL}(2.8-39.9)$

$15.9 \mu \mathrm{IU} / \mathrm{mL}(4.4-46.1)$

$2.2 \mathrm{ng} / \mathrm{dL}(3.0-23.6)$

$3.1 \mathrm{ng} / \mathrm{dL}(3.0-35.3)$

$0.551 \mathrm{ng} / \mathrm{mL}(0.104-0.548)$

$<0.005 \mathrm{ng} / \mathrm{mL}(0.02-0.08)$

$<0.005 \mathrm{ng} / \mathrm{mL}(<0.03)$

$0.57 \mu \mathrm{g} / 24 \mathrm{~h}(1.19-28.1)$

$0.37 \mathrm{pmol} / \mathrm{L}(<0.25)$

mutation by MutationTaster2 analysis. Furthermore, the identified mutation was not found in 300 unrelated normal controls. This variant was not found in the Exome Aggregation Consortium, the 1000 Genomes Project database or the Human Gene Mutation Database. Hence, we considered this frameshift mutation as novel. There were no other mutations in the sequenced 13th exon of SCNN1A or SCNN1G in any of the participants.

\section{Tailored therapy for LS patients}

LS patients are nonresponsive to spironolactone treatment $(10,11)$. The specific treatments for LS patients are $\mathrm{ENaC}$ blockers acting as $\mathrm{K}^{+}$-sparing diuretics, such as amiloride and triamterene $(11,12)$. In China, however, only combinations of hydrochlorothiazide and amiloride or triamterene are available. Based on the genetic results, 11 of the 13 mutation carriers (excluding individuals IV-12 and V-8 who refused medication) were treated with a compound of amiloride that contained hydrochlorothiazide (50 mg daily) and amiloride (5 mg daily). After a month, all treated patients recovered normal levels of BP and serum electrolytes (Table 2).

\section{Discussion}

Here, we report a novel frameshift mutation in $\beta$-ENaC with LS. Genetic investigation of the c.1838delC mutation showed that it is a gain-of-function mutation by altering the PY motif. This allowed a definite diagnosis of LS among all forms of monogenic hypertension.

Amiloride-sensitive ENaC mainly localizes in the apical portion of epithelial cells of the distal nephron, contributing to electrolytes homeostasis together with the renal outer

Mutant

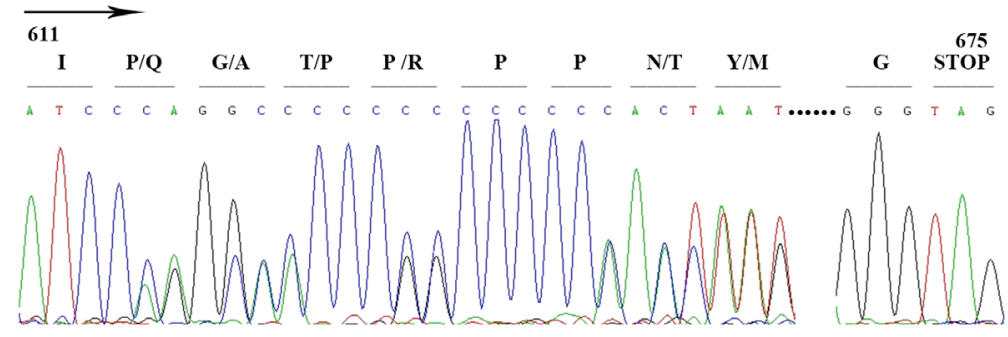

Wildtype

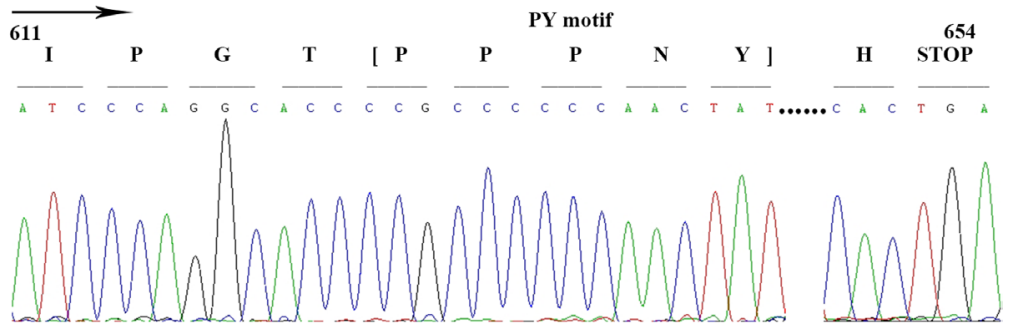

Figure 2

Sanger sequencing of exon 13 in SCNN1B shows a heterozygous frameshift mutation c.1838delC which deletes the PY motif and generates a new stop codon at position 675 .

https://ec.bioscientifica.com

https://doi.org/10.1530/EC-18-0484 (c) 2018 The authors Published by Bioscientifica Ltd

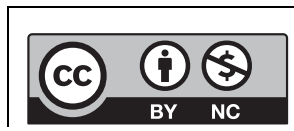

This work is licensed under a Creative Commons Attribution-NonCommercial 4.0 International License. 
Table 2 Clinical and biochemical characteristics of the patients with Liddle syndrome.

\begin{tabular}{|c|c|c|c|c|c|c|c|c|}
\hline \multirow[b]{2}{*}{ Patient } & \multirow[b]{2}{*}{ Gender } & \multirow[b]{2}{*}{ Onset age (years) } & \multirow[b]{2}{*}{ BP $\max (\mathrm{mmHg})$} & \multirow[b]{2}{*}{ Serum $\mathbf{K}^{+}(\mathrm{mmol} / \mathrm{L})$} & \multirow[b]{2}{*}{ PAC (ng/dL) } & \multirow[b]{2}{*}{ PRC $(\mu \mathrm{lU} / \mathrm{mL})^{\mathbf{b}}$} & \multicolumn{2}{|c|}{ Amiloride treatment ${ }^{a}$} \\
\hline & & & & & & & $\mathrm{BP}(\mathrm{mmHg})$ & Serum $\mathrm{K}^{+}(\mathrm{mmol} / \mathrm{L})$ \\
\hline III-3 & $\mathrm{F}$ & 50 & $180 / 88$ & 4.38 & 4.6 & 3.2 & $130 / 80$ & 4.67 \\
\hline III-4 & $\mathrm{M}$ & 56 & $171 / 85$ & 3.31 & 2.5 & 7.1 & $123 / 80$ & 4.23 \\
\hline III-8 & $\mathrm{F}$ & 51 & $182 / 130$ & 3.18 & 3.1 & 0.9 & $133 / 85$ & 3.98 \\
\hline III-10 & $\mathrm{F}$ & 46 & $153 / 105$ & 3.74 & 5.0 & 18.4 & $120 / 80$ & 4.55 \\
\hline IV-1 & $\mathrm{M}$ & 30 & $180 / 121$ & 4.24 & 3.8 & 0.7 & $127 / 80$ & 5.12 \\
\hline IV-5 & $\mathrm{M}$ & 20 & $180 / 130$ & 3.38 & 2.2 & 4.6 & $130 / 90$ & 4.94 \\
\hline IV-9 & $\mathrm{F}$ & 28 & $151 / 110$ & 3.88 & 2.0 & 1.7 & $125 / 83$ & 4.73 \\
\hline IV-12 & $\mathrm{F}$ & 20 & $140 / 95$ & 3.56 & 3.3 & 60.2 & - & - \\
\hline IV-15 & $\mathrm{M}$ & 20 & $220 / 140$ & 2.86 & 3.1 & 15.9 & $130 / 88$ & 5.09 \\
\hline V-2 & $\mathrm{F}$ & 8 & $122 / 82$ & 3.45 & 2.3 & 0.5 & $115 / 75$ & 4.35 \\
\hline V-3 & $\mathrm{M}$ & 6 & $141 / 84$ & 2.80 & 2.0 & 1.1 & $110 / 70$ & 3.87 \\
\hline V-5 & $\mathrm{F}$ & 3 & $112 / 51$ & 4.26 & 2.5 & 11.0 & $90 / 40$ & 4.90 \\
\hline V-8 & $\mathrm{M}$ & 3 & $100 / 53$ & 3.79 & 2.4 & 9.5 & - & - \\
\hline
\end{tabular}

aThe patients took compound amiloride combined with hydrochlorothiazide; ${ }^{\text {bPAC }}$ and PRC were measured after the patients kept upright position for $2 \mathrm{~h}$.

$\mathrm{BP}$, blood pressure; $\mathrm{F}$, female; $\mathrm{K}^{+}$, potassium; $\mathrm{M}$, male; PAC, plasma aldosterone concentration, normal range: $3.0-35.3 \mathrm{ng} / \mathrm{dL}$; $\mathrm{PRC}$, plasma renin concentration, normal range: $4.4-46.1 \mu \mathrm{IU} / \mathrm{mL}$.

medullary $\mathrm{K}^{+}$channels and $\mathrm{Na}^{+} / \mathrm{K}^{+}$ATPase (5). Electrogenic reabsorption of sodium by $\mathrm{ENaC}$ provides the driving force for chloride reabsorption by paracellular flux and potassium secretion by the renal outer medullary $\mathrm{K}^{+}$channels (13). Three homologous subunits share 30-40\% identity, and each one comprises an extracellular loop, two transmembrane domains and a short intracellular N-terminus and C-terminus (5). The PY motif, located within the C-terminus, is a crucial binding site for ubiquitin ligase Nedd4-2 (14). LS is mainly caused by missense mutations that alter an amino acid in the PY motif of $\beta$-ENaC or $\gamma$-ENaC and nonsense or frameshift mutations that delete the PY motif (12). These mutations disrupt ubiquitin ligase Nedd4-2 binding to the PY motif (15). This results in an increase in the number of $\mathrm{ENaC}$ at the cell surface, as well as increasing the probability of the ENaC being open, leading to increased $\mathrm{Na}^{+}$reabsorption and decreased serum potassium concentration (4). In this study, a novel frameshift mutation resulted in elongation of the C-terminus leading to the direct loss of the PY motif in $\beta$-ENaC.

Previously, 24 SCNN1B mutations have been reported to be associated with LS, including missense, nonsense, frameshift mutations, which include insertion and deletion mutations (4). There have been only three reported cases of LS caused by deletion mutations in $\beta$-ENaC. A deletion of 32 nucleotides (1735-1766) in $\beta$-ENaC introduces a stop codon at position 582 and causes a $3.7 \pm 0.3$-fold increase in the amoloride-sensitive sodium current (16). Freercks et al. described a deletion (c.1709del11) in $\beta$-ENaC associated with early-onset hypokalemia and resistant hypertension in a black
African male (17). Only one study has reported a small deletion mutation (c.1789delC) with LS that created an extended open reading frame until position 675 rather than a stop codon at position 654 (18). Theoretically, a single nucleotide deletion before the PY motif sequence may delete the PY motif and generate a new stop codon at position 675. This speculation is consistent with our experimental results.

Clinically, LS is characterized by phenotypic heterogeneity in terms of hypertension, hypokalemia and low PAC or PRC. Gong et al. concluded that LS patients with the same mutations could present various phenotypes even in one family, by comparison of the phenotypes in patients with two SCNN1B mutations (p.Arg566* and p.Arg597Profs*607) in previous studies (19). Analysis of a total of 54 genetically confirmed probands with LS showed the probability of various phenotypes, including hypertension (100\%), hypokalemia (94\%), suppressed PAC (84\%), suppressed PRC (94\%), and family history (86\%) (20). Systematic review by Tetti et al. revealed a prevalence of hypertension of $94.2 \%$, hypokalemia (defined as serum $\mathrm{K}+<3.5 \mathrm{mmol} / \mathrm{L}$ ) of $71.8 \%$ and hypoaldosteronemia (defined as serum aldosterone $<5 \mathrm{ng} / \mathrm{dL}$ ) of $58.2 \%$ (12). In our study family, SCNN1B mutation carriers manifested different levels of hypertension (13/13), hypokalemia (6/13), low PAC (7/13) and low PRC (6/13). In terms of hypokalemia, low PAC and low PRC, our study is consistent with previous summary studies. The different phenotypes suggest variable expressivity, possibly associated with gender, environmental factors or genetic modifiers (21). https://ec.bioscientifica.com

https://doi.org/10.1530/EC-18-0484 (c) 2018 The authors Published by Bioscientifica Ltd
This work is licensed under a Creative Commons Attribution-NonCommercial 4.0 International License. 
Phenotypic heterogeneity greatly increases the diagnostic difficulty and probability of misdiagnosis of LS. Initially, the proband was misdiagnosed with PA because of the symptoms of hypertension and hypokalemia, and false-positive confirmatory testing by saline infusion and captopril challenge testing. However, hypokalemia is not a sensitive marker of PA, as only a $9-37 \%$ overall incidence of hypokalemia has been reported in PA patients $(22,23)$. Secondly, many factors may disturb ARR, including volume status, age, potassium, time of day and antihypertensive use (24). Facing these problems, the absolute aldosterone levels are also taken into account when measuring ARR. An elevated aldosterone level (PAC $>15 \mathrm{ng} / \mathrm{mL}$ or $420 \mathrm{pmol} / \mathrm{L}$ ) should be combined with the elevated ARR to confirm a truly positive screening test (25). Monogenic hypertension is also seen in several diseases that are clinically similar to LS, such as apparent mineralocorticoid excess, familial PA and congenital adrenal hyperplasia. All these disorders may present with early-onset hypertension, low potassium levels, suppressed renin and metabolic alkalosis (26). Genetic screening is therefore useful to identify these inherited hypertensions.

Additionally, LS is a rare inherited disorder and many clinicians may not be familiar with it. It has been estimated to have a prevalence of $<1$ in $10^{6}$ worldwide by Orphanet (http://www.orpha.net/consor/cgi-bin/ OC_Exp.php?Expert=526). Tapolyai et al. reported a likely LS prevalence of $6 \%$ in predominantly elderly male Caucasian patients who were diagnosed based on clinical and biochemical features without genetic evidence (27). According to genetic testing, two studies in China showed the lower prevalence of LS $(1.52 \%$ among hypokalemic hypertension patients aged 14-40 years (28) and $1.72 \%$ among low-renin earlyonset hypertension patients (29)). However, as genetic testing is not routine screening, the prevalence of LS may be higher than reported.

In conclusion, we have characterized a novel frameshift mutation in $\beta$-ENaC and emphasized the importance of genetic analysis for LS in terms of differential diagnosis. The increased availability of genetic screening will allow higher diagnostic accuracy, better documentation of phenotypic characteristics, appropriate therapy and the prevention of target organ damage and associated cardiovascular complications.

\section{Supplementary data}

This is linked to the online version of the paper at https://doi.org/10.1530/ EC-18-0484.

\section{Declaration of interest}

The authors declare that there is no conflict of interest that could be perceived as prejudicing the impartiality of the research reported.

\section{Funding}

This work was supported by CAMS Innovation Fund for Medical Sciences (2016-I2M-1-002), the National Key Research and Development Program of China (2016YFC1300100), National Natural Science Foundation of China (81600305, 81400187 and 81230015), Beijing Municipal Science and Technology Commission (NO.Z151100003915078) and PUMC Graduate Innovation Fund (2018-1002-01-14).

\section{Acknowledgements}

The authors thank all the patients and the families in this study for their collaboration.

\section{References}

1 Jain G, Ong S \& Warnock DG. Genetic disorders of potassium homeostasis. Seminars in Nephrology 201333 300-309. (https://doi. org/10.1016/j.semnephrol.2013.04.010)

2 Zennaro MC, Boulkroun S \& Fernandes-Rosa F. Inherited forms of mineralocorticoid hypertension. Best Practice and Research: Clinical Endocrinology and Metabolism 201529 633-645. (https://doi. org/10.1016/j.beem.2015.04.010)

3 Assadi F. Diagnosis of hypokalemia: a problem-solving approach to clinical cases. Iranian Journal of Kidney Diseases 20082 115-122.

4 Yang KQ, Xiao Y, Tian T, Gao LG \& Zhou XL. Molecular genetics of Liddle's syndrome. Clinica Chimica Acta 2014436 202-206. (https:// doi.org/10.1016/j.cca.2014.05.015)

5 Canessa CM, Schild L, Buel G, Thorens B, Gautschi I, Horisberger JD \& Rossier BC. Amiloride-sensitive epithelial Na+ channel is made of three homologous subunits. Nature 1994367 463-467. (https://doi. org/10.1038/367463a0)

6 Schild L, Lu Y, Gautschi I, Schneeberger E, Lifton RP \& Rossier BC. Identification of a PY motif in the epithelial $\mathrm{Na}$ channel subunits as a target sequence for mutations causing channel activation found in Liddle syndrome. EMBO Journal 199615 2381-2387. (https://doi. org/10.1002/j.1460-2075.1996.tb00594.x)

7 Yang KQ, Lu CX, Xiao Y, Liu YX, Jiang XJ, Zhang X \& Zhou XL. A novel frameshift mutation of epithelial sodium channel beta-subunit leads to Liddle syndrome in an isolated case. Clinical Endocrinology 201582 611-614. (https://doi.org/10.1111/cen.12650)

$8 \mathrm{Li} \mathrm{H} \&$ Durbin R. Fast and accurate short read alignment with Burrows-Wheeler transform. Bioinformatics 200925 1754-1760. (https://doi.org/10.1093/bioinformatics/btp324)

9 Wang K, Li M \& Hakonarson H. ANNOVAR: functional annotation of genetic variants from high-throughput sequencing data. Nucleic Acids Research 201038 e164. (https://doi.org/10.1093/nar/gkq603)

10 Cui Y, Tong A, Jiang J, Wang F \& Li C. Liddle syndrome: clinical and genetic profiles. Journal of Clinical Hypertension 201719 524-529. (https://doi.org/10.1111/jch.12949)

11 Mulatero P, Verhovez A, Morello F \& Veglio F. Diagnosis and treatment of low-renin hypertension. Clinical Endocrinology $2007 \mathbf{6 7}$ 324-334. (https://doi.org/10.1111/j.1365-2265.2007.02898.x)

12 Tetti M, Monticone S, Burrello J, Matarazzo P, Veglio F, Pasini B, Jeunemaitre X, Mulatero P. Liddle syndrome: review of the literature and description of a new case. International Journal of Molecular Sciences 201819 1-15. (https://doi.org/10.3390/ijms19030812)

13 Gaukrodger N, Avery PJ \& Keavney B. Plasma potassium level is associated with common genetic variation in the beta-subunit of the epithelial sodium channel. American Journal of Physiology. Regulatory,

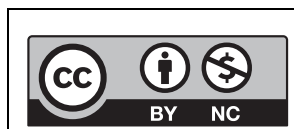

This work is licensed under a Creative Commons Attribution-NonCommercial 4.0 International License. 
Integrative and Comparative Physiology 2008294 1068-1072. (https:// doi.org/10.1152/ajpregu.00732.2007)

14 Hanukoglu I \& Hanukoglu A. Epithelial sodium channel (ENaC) family: Phylogeny, structure-function, tissue distribution, and associated inherited diseases. Gene 2016579 95-132. (https://doi. org/10.1016/j.gene.2015.12.061)

15 Rotin D \& Staub O. Role of the ubiquitin system in regulating ion transport. Pflugers Archiv 2011461 1-21. (https://doi.org/10.1007/ s00424-010-0893-2)

16 Jeunemaitre X, Bassilana F, Persu A, Dumont C, Champigny G, Lazdunski M, Corvol P \& Barbry P. Genotype-phenotype analysis of a newly discovered family with Liddle's syndrome. Journal of Hypertension 199715 1091-1100. (https://doi.org/10.1097/00004872199715100-00007)

17 Freercks R, Meldau S, Jones E, Ensor J, Weimers-Willard C \& Rayner B. Liddle's syndrome in an African male due to a novel frameshift mutation in the beta-subunit of the epithelial sodium channel gene. Cardiovascular Journal of Africa 201728 4-6. (https:// doi.org/10.5830/CVJA-2017-012)

18 Shimkets RA, Warnock DG, Bositis CM, Nelson-Williams C, Hansson JH, Schambelan M, Gil JR Jr, Ulick S, Milora RV, Findling JW, et al. Liddle's syndrome: heritable human hypertension caused by mutations in the beta subunit of the epithelial sodium channel. Cell 199479 407-414. (https://doi.org/10.1016/00928674(94)90250-X)

19 Gong L, Chen J, Shao L, Song W, Hui R \& Wang Y. Phenotypegenotype analysis in two Chinese families with Liddle syndrome. Molecular Biology Reports 201441 1569-1575. (https://doi. org/10.1007/s11033-013-3003-7)

20 Yang KQ, Lu CX, Fan P, Zhang Y, Meng X, Dong XQ, Luo F, Liu YX, Zhang HM, Wu HY, et al. Genetic screening of SCNN1B and SCNN1G genes in early-onset hypertensive patients helps to identify Liddle syndrome. Clinical and Experimental Hypertension 201840 107-111. (https://doi.org/10.1080/10641963. 2017.1334799)

21 Bogdanovic R, Kuburovic V, Stajic N, Mughal SS, Hilger A, Ninic S, Prijic S \& Ludwig M. Liddle syndrome in a Serbian family and literature review of underlying mutations. European Journal of
Pediatrics 2012171 471-478. (https://doi.org/10.1007/s00431-0111581-8)

22 Rossi GP, Bernini G, Caliumi C, Desideri G, Fabris B, Ferri C, Ganzaroli C, Giacchetti G, Letizia C, Maccario M, et al. A prospective study of the prevalence of primary aldosteronism in 1,125 hypertensive patients. Journal of the American College of Cardiology 200648 2293-2300. (https://doi.org/10.1016/j.jacc.2006.07.059)

23 Mulatero P, Stowasser M, Loh KC, Fardella CE, Gordon RD, Mosso L, Gomez-Sanchez CE, Veglio F, Young WF Jr. Increased diagnosis of primary aldosteronism, including surgically correctable forms, in centers from five continents. Journal of Clinical Endocrinology and Metabolism 200489 1045-1050. (https://doi.org/10.1210/jc.2003031337)

24 Galati SJ. Primary aldosteronism: challenges in diagnosis and management. Endocrinology and Metabolism Clinics of North America 201544 355-369. (https://doi.org/10.1016/j.ecl.2015.02.010)

25 Gyamlani G, Headley CM, Naseer A, Valaulikar GS \& Geraci SA. Primary aldosteronism: diagnosis and management. American Journal of the Medical Sciences 2016352 391-398. (https://doi.org/10.1016/j. amjms.2016.06.015)

26 Simonetti GD, Mohaupt MG \& Bianchetti MG. Monogenic forms of hypertension. European Journal of Pediatrics 2012171 1433-1439. (https://doi.org/10.1007/s00431-011-1440-7)

27 Tapolyai M, Uysal A, Dossabhoy NR, Zsom L, Szarvas T, Lengvarszky Z \& Fulop T. High prevalence of liddle syndrome phenotype among hypertensive US Veterans in Northwest Louisiana. Journal of Clinical Hypertension 201012 856-860. (https://doi. org/10.1111/j.1751-7176.2010.00359.x)

28 Wang LP, Yang KQ, Jiang XJ, Wu HY, Zhang HM, Zou YB, Song L, Bian J, Hui RT, Liu YX, et al. Prevalence of Liddle syndrome among young hypertension patients of undetermined cause in a Chinese population. Journal of Clinical Hypertension 201517 902-907. (https://doi.org/10.1111/jch.12598)

29 Liu K, Qin F, Sun X, Zhang Y, Wang J, Wu Y, Ma W, Wang W, Wu X, Qin Y, et al. Analysis of the genes involved in Mendelian forms of low-renin hypertension in Chinese early-onset hypertensive patients. Journal of Hypertension 201836 502-509. (https://doi.org/10.1097/ HJH.0000000000001556)

Received in final form 20 November 2018

Accepted 28 November 2018

Accepted Preprint published online 28 November 2018

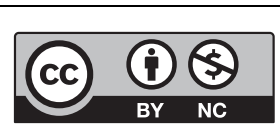

This work is licensed under a Creative Commons Attribution-NonCommercial 4.0 International License. 